\title{
Correction to: Cytoplasmic sirtuin 6 translocation mediated by 162 polyubiquitination plays a critical role in cadmium-induced kidney toxicity
}

\author{
Keum-Young So • Byung-Hyun Park • Seon-Hee Oh
}

Published online: 22 August 2020

(C) Springer Nature B.V. 2020

\section{Correction to: Cell Biol Toxicol \\ https://doi.org/10.1007/s10565-020-09528-2}

In the original publication the grant number is incorrectly published. The correct grant number should be read as "NRF-2016R1D1A1B01012037". The corrected contents are provided in this correction article below.

Funding information This research was supported by Basic Science Research Program through the National Research Foundation of Korea (NRF) funded by the Ministry of Education (NRF-2016R1D1A1B01012037) and by grants from the Medical Research Center Program (NRF-2017R1A5A2015061) through the National Research Foundation (NRF), which is funded by the Korean government (MSIP) and grants from the Clinical Medcine Research Institute at Chosun University Hospital (2015).

Publisher's note Springer Nature remains neutral with regard to jurisdictional claims in published maps and institutional affiliations.

The online version of the original article can be found at https://doi.org/10.1007/s10565-020-09528-2

\section{K.-Y. So}

Department of Anesthesiology and Pain Medicine, School of Medicine, Chosun University, 309 Pilmundaero, Dong-gu, Gwangju 501-759, South Korea

\section{B.-H. Park}

Department of Biochemistry, Chonbuk National University Medical School, Jeonju, Jeonbuk, Republic of Korea

S.-H. Oh $(\bowtie)$

School of Medicine, Chosun University, 309 Pilmundaero,

Dong-gu, Gwangju 501-759, South Korea

e-mail: seonh@chosun.ac.kr 